\title{
OXYANION SURFACE COVERAGE CONTROLS THE RATE AND PATHWAY OF FERRIHYDRITE TRANSFORMATION
}

\author{
ALIREZA NAMAYANDEH ${ }^{1}$, STEVEN WATSON ${ }^{1}$, OLAF J \\ BORKIEWICZ ${ }^{2}$ AND F. MARC MICHEL ${ }^{1}$ \\ ${ }^{1}$ Virginia Tech \\ ${ }^{2}$ Argonne National Laboratory \\ Presenting Author: anamayandeh@vt.edu
}

Ferrihydrite $(\mathrm{Fh})$ is a metastable iron hydroxide nanoparticle that transforms to crystalline iron (hydr)oxides goethite (Gt) and hematite $(\mathrm{Hm})$ under oxic conditions. In natural environments, Fh reacts readily with oxyanions such as $\mathrm{PO}_{4}^{-3}$ and $\mathrm{AsO}_{4}^{-3}$ mainly through inner-sphere complexation. While past experiments show that the mode and strength of oxyanion complexes control the rate and pathway of Fh transformation, the impact of oxyanion surface coverage on this process is only partly understood. We have developed a kinetic model that describes the impact of $\mathrm{AsO}_{4}{ }^{-3}$ and $\mathrm{PO}_{4}^{-3}$ surface coverage on the kinetics and pathway of $\mathrm{Fh}$ transformation. Fh was synthesized and reacted with known concentrations $(0.2,0.6,1.0,5.0 \mathrm{mM})$ of $\mathrm{AsO}_{4}{ }^{-3}$ and $\mathrm{PO}_{4}{ }^{-3}$ by mixing and shaking samples for 24 hours. The oxyanion-adsorbed $\mathrm{Fh}$ samples were then buffered at $\mathrm{pH} 5.5$ \pm 0.2 , aged for up to 50 days at $70 \pm 1.5^{\circ} \mathrm{C}$, and characterized using synchrotron powder x-ray diffraction (pXRD) and pair distribution function (PDF) analysis with linear combination fitting (LCF). Kinetic modeling showed that the rate of Fh transformation decreases with increasing oxyanion concentration such that no transformation occurred for samples with the highest oxyanion surface coverage $(5.0 \mathrm{mM})$. Results also showed how increasing oxyanion surface coverage impacted the $\mathrm{Fh}$ transformation pathway by favoring $\mathrm{Hm}$ over Gt. This study demonstrates how oxyanion surface coverage can influence the rate and pathway of Fh transformation. 